\title{
Tratamento Odontológico em Pacientes com Câncer durante a Pandemia de Covid-19
}

doi: https://doi.org/10.32635/2176-9745.RBC.2020v66nTemaAtual.1005

\author{
Dental Treatment in Cancer Patients during the COVID-19 Pandemic \\ El Tratamiento Dental en Pacientes con Cáncer durante la Pandemia de Covid-19
}

\author{
Adriele de Freitas Neiva Lessa'; Alice Muglia Tomaz da Silva Amancio²; Lucas Alves da Mota Santana³; Maria Cássia Ferreira de \\ Aguiar $^{4}$
}

\section{INTRODUÇÃO}

O surto da atual pandemia de coronavírus surgiu em Wuhan, na China, e rapidamente evoluiu, espalhando-se exponencialmente para outras partes do mundo ${ }^{1}$. O novo coronavírus (2019-nCoV), vetor responsável pela síndrome respiratória aguda grave do coronavírus 2 (severe acute respiratory syndrome coronavirus 2 - Sars-CoV-2), pertence a uma família de vírus de RNA de fita simples, conhecidos como Coronaviridae ${ }^{2}$. Filogeneticamente, essa nova espécie compartilha similaridades com outros coronavírus, como Mers-CoV e Sars-CoV, ambos os responsáveis por síndromes respiratórias ${ }^{3}$. A etiologia do Sars-CoV-2 permanece incerta, contudo, essa família de vírus é conhecida por ser zoonótica, isto é, transmitida de animais para seres humanos ${ }^{4}$.

As rotas de transmissão comuns da doença pelo coronavírus 2019 (coronavirus disease 2019 - Covid-19) incluem transmissão direta (tosse, espirro e inalação de gotículas) e transmissão de contato (contato com a via oral, nasal e mucosas oculares) $)^{5,6}$. Observaçōes recentes sugerem que pacientes assintomáticos e pacientes em período de incubação também são portadores de Sars-CoV-2, se tornando fonte de transmissão, assim como os pacientes sintomáticos ${ }^{7,8}$. Infelizmente, não há até o momento vacina ou tratamentos farmacológicos específicos, e a única alternativa disponível é a suplementação de oxigênio aos pacientes sintomáticos ${ }^{9}$. Como a odontologia é uma área que trabalha em íntimo contato com as vias respiratórias do paciente (boca e nariz), o cirurgião-dentista aparece no topo dos profissionais com alta chance de contágio pela Covid- $19^{10}$. Sars-CoV-2 é um agente altamente infeccioso, com capacidade de propagação pelo ar, por meio de gotículas (geradas por tosse, espirro de pacientes infectados e saliva), ou transmitido por muitos procedimentos que produzem aerossol, saliva ou sangue do paciente ${ }^{11,12}$. Soma-se a isso a sua elevada capacidade de resitência no ambiente, com viabilidade variando de horas a dias ${ }^{13}$. Diante desse cenário, de alta chance de contágio pelo profissional e equipe, a American Dental Association ${ }^{14}$ aconselha realizar apenas procedimentos odontológicos de emergência e adiar tratamentos eletivos ${ }^{15}$.

Contudo, existe um grupo de pacientes que, apesar de toda adversidade do momento, necessita de acompanhamento e cuidados odontológicos, que são os pacientes com câncer. Esse grupo, em especial, é mais suscetível à infecção do que indivíduos sem câncer, em razão do seu estado de imunossupressão sistêmica causado pelo tumor e tratamento oncológico, como quimioterapia ou cirurgia ${ }^{16}$. No estudo conduzido por Liang et al. ${ }^{17}$ com 18 pacientes, foi obervado que pacientes com câncer podem ter risco aumentado para Covid-19 e, subsequentemente, um pior prognóstico. Sendo assim, o objetivo do presente artigo é discutir as principais medidas que podem ser adotadas pelos profissionais da saúde bucal, que garantam assistência segura e adequada a pacientes oncológicos durante o período de pandemia.

\section{DESENVOLVIMENTO}

Até o momento, são desconhecidos protocolos com orientaçóes sobre Covid-19 voltados ao tratamento odontológico em pacientes com câncer, especialmente

${ }^{1}$ Cirurgiã-Dentista e Pesquisadora do Hospital do Câncer de Muriaé. Doutoranda em Estomatologia pela Universidade Federal de Minas Gerais (UFMG). Belo Horizonte (MG), Brasil. Orcid iD: https://orcid.org/0000-0003-4784-2881

${ }^{2}$ Bióloga. Pós-doutorado em Imunologia pelo National Institute Health (NIH). Pesquisadora do Hospital do Câncer de Muriaé. Muriaé (MG), Brasil. Orcid iD: https:// orcid.org/0000-0003-1098-8799

${ }^{3}$ Cirurgião-Dentista. Mestre em Clínica Odontológica pela Universidade Federal de Sergipe (UFS). Departamento de Odontologia da UFS. Aracaju (SE), Brasil. Orcid iD: https://orcid.org/0000-0002-8261-1504

${ }^{4}$ Cirurgiã-Dentista. Chefe do Departamento de Clínica, Patologia e Cirurgia. Professora-Titular da UFMG. Belo Horizonte (MG), Brasil. Orcid iD: https://orcid.org/00000001-5134-3466

Endereço para correspondência: Adriele de Freitas Neiva Lessa. Rua São Jerônimo, 132, apto. 502 - Sagrada família. Belo Horizonte (MG), Brasil. CEP $31035-490$. E-mail: drineiva@hotmail.com 
com câncer na região de cabeça e pescoço. É sabido que esses pacientes podem apresentar algumas particularidades e desenvolver complicaçóes correlatas oriundas da terapia anticâncer, como mucosite, infecçôes bacterianas e fúngicas oportunistas, e alteraçấo no fluxo salivar ${ }^{18}$. Em geral, essa saliva é mais viscosa e pegajosa e, juntamente com a disfagia, pode dificultar na deglutição, obrigando-os a lançar mão de artíficios, como toalhas para descarte dessa saliva, além do uso de sonda nasoentéricas ${ }^{19,20}$. Situaçóes que podem facilitar a propagação viral, uma vez que, como reportado recentemente, a saliva pode ser reservatório de elevada carga viral para Sars-CoV-2 e funcionar como potencial veículo de propagaçáo do patógeno tanto aos integrantes da equipe odontológica quanto aos pacientes e ao ambiente de trabalho ${ }^{12,15}$.

Por isso, advoga-se que uma adequada anamnese e uma segura atenção odontológica são imperativas neste momento. Muitos pacientes podem ser Sars-CoV-2 positivos e apresentar sintomas leves a moderados, ou ser totalmente assintomáticos. Por esse motivo, os pacientes podem ser tratados em uma sala isolada e bem ventilada, ou negativamente pressurizadas, evitando sempre aglomeraçãoo ${ }^{15,21}$. Atualmente, os protocolos de atendimento clínico têm orientado à triagem prévia desses pacientes, incluindo questionamentos sobre o estado de sáude geral e exames físicos, como medição da temperatura corporal $^{12,15}$. Os pacientes que apresentarem sinais e sintomas compatíveis com quadro gripal, como tosse, cansaço, febre e falta de ar, devem ser encaminhados ao hospital ou a serviços de pronto-atendimento ${ }^{12}$.

Além desses cuidados adicionais, torna-se imprescindível manter, para o tratamento odontológico, as mesmas orientaçôes destinadas ao tratamento odontológico de maneira geral, como a correta paramentação da equipe, higienização das mãos e do ambiente $^{12,21}$. A higienizaçáo das mãos deve ser feita com água e sabonete líquido ou preparação alcoólica (70\%). Além dessas medidas iniciais, recomenda-se o uso dos equipamentos de proteçáo individual (EPI), entre estes, o uso de respiradores de partículas, como máscaras N-95 ou máscaras-padrão PFF 2, em razão das gotículas respiratórias que são a principal via de transmissão do Sars-CoV-2 $2^{21}$. Já o uso de luvas, aventais descartáveis, gorros, óculos e protetores faciais tem o intuito de proteger a pele e a mucosa em contato com sangue ou secreção (potencialmente) infectados ${ }^{8,12,21}$.

A inspeção intraoral é mandatória para pacientes oncológicos, sobretudo por garantir a manutenção da saúde bucal como higiene, profilaxia oral e controle da placa. No entanto, o antisséptico de uso cotidiano na clínica odontológica, clorexidina, mostrou-se ineficaz no combate ao agente viral. Como o Sars-CoV-2 é um microrganismo dotado de revestimento proteico ${ }^{3}$, apenas soluçôes alcoólicas e oxidantes apresentam significativa ação microbicida de solubilização, como álcool (70\%), hipoclorito de sódio $(0,5 \%)$ e peróxido de hidrogênio $(0,1 \%)^{13}$. Tendo em vista a capacidade germicida dessas substâncias e sabendo do potencial risco de contágio por meio do fluido salivar e de gotículas dispersas no meio, sugere-se o uso do peróxido de hidrogênio diluído a $1 \%$ ou povidona a $0,2 \%$, para bochechos vigorosos por 1 minuto, como solução antisséptica. Essas medidas visam a reduzir a carga salivar de microrganimos orais, incluindo o seu potencial transporte. Como objeção, orienta-se o não uso contínuo dessas substâncias, exceto nas inspeçóes odontológicas de rotina ${ }^{12}$.

Seguindo as orientaçôes de biossegurança e controle sanitário, os atendimentos odontológicos encontram-se restritos aos procedimentos de urgência e emergência ${ }^{12}$. Inclusive nessas situaçôes, a utilização de equipamentos que produzem aerossóis deve ser minimizada. É indicado também o uso de sugador de alta potência e se possível isolamento com dique de borracha, sendo vantajoso o cobrimento do nariz ${ }^{14,15}$. O uso de instrumentos ultrassônicos de alta rotação, peças de mão e seringa tríplice deve ser evitado ${ }^{14}$.

As extrações dentárias podem tornar-se necessárias em alguns casos, sobretudo pelo fato de que muitos desses pacientes são submetidos à radioterapia e à quimioterapia. Em vista disso, é importante destacar que esses tratamentos podem influenciar diretamente na fisiologia e metabolismo ósseo, tornando os pacientes mais suscetíveis à infecçẫo e, por conseguinte, em maior risco de osteorradionecrose e osteonecrose dos maxilares ${ }^{22}$. Nessas situaçôes, dar preferência a suturas absorvíveis.

Após a finalização dos procedimentos odontológicos, recomenda-se a limpeza e a desinfecção do ambiente com soluções germicidas, como etanol (70\%) e hipoclorito de sódio $(0,1 \%)$, pois, se não forem realizadas de maneira adequada, todo o processo pode ser comprometido ${ }^{23-24}$. Para desparamentação, a sequência cronológica inclui remoção das luvas, óculos/protetor facial, capote e máscara ${ }^{23-24}$. Nesse cenário desafiador da Covid-19, segundo Lopes et al. ${ }^{25}$, a assistência virtual aos pacientes e profissionais de saúde, principalmente para os dentistas, poderia ajudar a priorizar casos de maior risco, evitando o contato pessoal e ajudando a preservar os recursos durante esse período preocupante. Outro ponto que necessita ser levantado é em relação aos atrasos que podem ocorrer na entrega de exames laboratoriais (patologia) e de imagens (radiografia panorâmica), uma vez que é esperado que muitos estejam trabalhando parcialmente ${ }^{25}$. O momento atual é um desafio multifatorial, sendo necessária a atenção especial para pacientes com câncer. 


\section{CONCLUSÃO}

Mesmo diante da pandemia pela Covid-19 e dos desafios que ela oferece à atenção odontológica, especialmente aos grupos vulneráveis, esse atendimento poderá ser realizado com as devidas informaçóes e cuidados. Por isso, é extremamente importante se manter informado com conhecimento de qualidade e desenvolvimento de uma análise crítica, para encontrar o equilíbrio entre a necessidade de intervenção e a menor exposição dos pacientes oncológicos a situaçóes de risco.

\section{CONTRIBUIÇÕES}

Adriele de Freitas Neiva Lessa contribuiu substancialmente na concepção e planejamento do estudo; na obtenção, na análise e/ ou interpretaçáo dos dados; assim como na redação e/ou revisão crítica. Alice Muglia Tomaz da Silva Amancio, Lucas Alves da Mota Santana e Maria Cássia Ferreira de Aguiar contribuíram na obtenção, na análise e/ou interpretação dos dados; assim como na redação e/ou revisão crítica. Todos os autores aprovaram a versão final a ser publicada.

\section{DECLARAÇÃO DE CONFLITO DE INTERESSES}

Nada a declarar.

\section{FONTES DE FINANCIAMENTO}

Não há.

\section{REFERÊNCIAS}

1. Dong E, Du H, Gardner L. An interactive web-based dashboard to track COVID-19 in real time. Lancet Infect Dis. 2020 Feb 19. doi: https://doi.org/10.1016/ S1473-3099(20)30120-1

2. Fehr AR, Perlman S. Coronaviruses: an overview of their replication and pathogenesis. Methods Mol Biol. 2015;1282:1-23. doi: https://doi.org/10.1007/978-14939-2438-7_1

3. Andersen KG, Rambaut A, Lipkin WI, et al. The proximal origin of SARS-CoV-2. Nat Med. 2020;26:45052. doi: https://doi.org/10.1038/s41591-020-0820-9

4. Sun J, He WT, Wang L, et al. COVID-19: epidemiology, evolution, and cross-disciplinary perspectives. Trend Mol Med. 2020 Mar 21;1-32 doi: https://doi.org/10.1016/j. molmed.2020.02.008

5. Lu CW, Liu XF, Jia ZF. 2019-nCoV transmission through the ocular surface must not be ignored. Lancet. 2020;395(10224):e39. doi: https://doi.org/10.1016/ S0140-6736(20)30313-5
6. To KK, Tsang OT, Chik-Yan Yip C, et al. Consistent detection of 2019 novel coronavirus in saliva. Clin Infect Dis. 2020 Feb 12;pii:ciaa149. doi: https://doi. org/10.1093/cid/ciaa149

7. Chan JFW, Yuan S, Kok KH, et al. A familial cluster of pneumonia associated with the 2019 novel coronavirus indicating person-to-person transmission: a study of a family cluster. Lancet. 2020;395(10223):514-23. doi: https://doi.org/116/S0140-6736(20)30154-9

8. Rothe C, Schunk M, Sothmann P, et al. Transmission of 2019-nCoV infection from an asymptomatic contact in Germany. N Engl J Med. 2020;382:970-971. doi: https://doi.org/10.1056/NEJMc2001468

9. Sanders JM, Monogue ML, Jodlowski TZ, et al. Pharmacologic treatments for coronavirus disease 2019 (COVID-19): a review. JAMA. 2020 Apr 13. https:// doi.org/10.1001/jama.2020.6019.

10. Gamio L. The workers who face the greatest coronavirus risk. The NewYork Times [Internet]. 2020 Mar 15. [cited 2020 Apr 23]. Available from: https://www.nytimes.com/ interactive/2020/03/15/business/economy/coronavirusworker-risk.html

11. Sabino-Silva R, Jardim ACG, Siqueira WL. Coronavirus COVID-19 impacts to dentistry and potential salivary diagnosis. Clin Oral Investig. 2020;24(4):1619-21. doi: https://doi.org/10.1007/s00784-020-03248-x

12. Peng X, Xu X, Li Y, et al. Transmission routes of 2019$\mathrm{nCoV}$ and controls in dental practice. Int J Oral Sci. 2020;12(1):9. doi: https://doi.org/10.1038/s41368-0200075-9

13. Kampf G, Todt D, Pfaender S, et al. Persistence of coronaviruses on inanimate surfaces and their inactivation with biocidal agents. J Hosp Infect. 2020;104(3):246-51. doi: https://doi.org/10.1016/j.jhin.2020.01.022

14. American Dental Association [Internet]. Chicago: ADA; 2020. ADA develops guidance on dental emergency, nonemergency care: recommendations part of dentists' response over COVID-19 concerns; 2020 Mar 18 [cited 2020 Apr 23]. Available from: https://www.ada.org/en/ publications/ada-news/2020-archive/march/ada-developsguidance-on-dental-emergency-nonemergency-care

15. Meng L, Hua F, Bian Z. Coronavirus disease 2019 (COVID-19): emerging and future challenges for dental and oral medicine. J Dent Res. 2020;99(5):481-87. doi: https://doi.org/110.1177/0022034520914246

16. Sica A, Massarotti M. Myeloid suppressor cells in cancer and autoimmunity. J Autoimmun. 2017;85:117-25. doi: https://doi.org/10.1016/j.jaut.2017.07.010

17. Liang W, Guan W, Chen R, et al. Cancer patients in SARS-CoV-2 infection: a nationwide analysis in China. Lancet Oncol. 2020;21(3):335-37. doi: https://doi. org/10.1016/S1470-2045(20)30096-6

18. Wong HM. Oral complications and management strategies for patients undergoing cancer therapy. 
Sci World J. 2014;2014:581795. doi: https://doi. org/10.1155/2014/581795

19. Hong CHL, Hu S, Haverman T, et al. A systematic review of dental disease management in cancer patients. Support Care Cancer. 2018;26(1):155-74. https://doi. org/ 10.1007/s00520-017-3829-y

20. Patel V, Patel D, Browning T, et al. Presenting pre-radiotherapy dental status of head and neck cancer patients in the novel radiation era. Br Dent J. 2020;228(6):435-40. doi: https://doi.org/10.1038/ s41415-020-1327-y

21.Li ZY, Meng LY. [The Prevention and control of new coronavirus infection in department of stomatology]. Zhonghua Kou Qiang Yi Xue Za Zhi. 2020;55(0):E001. doi: https://doi.org/10.3760/ cma.j.issn.1002-0098.2020.0001 Epub ahead of print. Chinese.

22. De Antoni CC, Matsumoto MA, Silva AA, et al. Medication-related osteonecrosis of the jaw, osteoradionecrosis, and osteomyelitis: a comparative histopathological study. Braz Oral Res. 2018;32:e23. https://doi.org/10.1590/1807-3107bor-2018. vol32.0023

23. Thomé G, Bernardes SR, Guandalini S, et al. Manual de boas práticas em biossegurança para ambientes odontológicos [Internet]. Curitiba: JJGC Indústria e Comércio de Materiais Dentários S.A; [2020 abr]. [acesso 2020 abr 23]. Disponível em: http:// website.cfo.org.br/wp-content/uploads/2020/04/cfolanc\%CC $\% A 7$ a-Manual-de-Boas-Pra\%CC\%81 ticasem-Biosseguranc\%CC\%A7a-para-AmbientesOdontologicos.pdf

24. Centers for Disease Control and Prevention. Sequence for putting on personal protective equipment (PPE) [Internet]. Atlanta: CDC; [2020]. [cited 2020 Apr 23]. Available from: https://www.cdc.gov/hai/pdfs/ppe/ppesequence.pdf

25. Lopes MA, Santos-Silva AR, Vargas PA, et al. Virtual assistance in oral medicine for prioritizing oral cancer diagnosis during the COVID-19 pandemic. Oral Surg Oral Med Oral Pathol Oral Radiol. 2020 Apr 8. doi: https://doi.org/10.1016/j.oooo.2020.04.009. Epub ahead of print. 